\author{
Rebecca Schultz \\ Christiane Arndt-Bascle* \\ Paul Davidson* \\ Benjamin Gerloff*
}

\title{
BETTER INDICATORS FOR BETTER REGULATION: THE OECD iREG EXPERIENCE
}

The OECD Indicators of Regulatory Policy and Governance (iREG) are one of the world's leading indicators on better regulation. They measure OECD countries' progress in implementing regulatory policy practices as advocated in the 2012 Recommendation on Regulatory Policy and Governance and cover in detail requirements and practices in the areas of stakeholder engagement, Regulatory Impact Assessment (RIA) and ex post evaluation. This article describes how the OECD developed these indicators in co-operation with its member countries, presents key findings from the iREG's 2018 edition, and reflects on critical success factors that made them an invaluable tool to drive regulatory reform.

\section{Mejores indicadores para una regulación mejor: la experiencia iREG de la OCDE}

Los Indicadores de Política y Gobernanza Regulatoria (iREG) de la OCDE figuran entre los principales indicadores mundiales de mejora de la regulación. Miden el progreso de los países de la OCDE en la implementación de prácticas de política regulatoria como se aconseja en la Recomendación de 2012 sobre Política y Gobernanza Regulatoria y cubren en detalle los requisitos y prácticas en las áreas de involucración de partes interesadas, evaluación de impacto regulatorio (RIA) y evaluación ex post. Este artículo describe cómo la OCDE desarrolló estos indicadores en cooperación con sus países miembros, presenta los hallazgos clave de la edición 2018 de iREG y reflexiona sobre los factores críticos de éxito que los convirtieron en una herramienta de valor incalculable para impulsar la reforma regulatoria.

Keywords: methodology, international organization, regulation and industrial policy, comparative analysis. Palabras clave: metodología, organización internacional, regulación y política industrial, análisis comparativo.

JEL: C8, F5, K2, L5, O5.

\footnotetext{
* OECD Regulatory Policy Division.

The opinions expressed and arguments employed herein are those of the authors and do not necessarily reflect the official views of the OECD or of the Governments of its member countries.

Final version: 11 March 2019.

DOI: https://doi.org/10.32796/ice.2019.907.6806
} 


\section{Introduction}

What gets measured, gets done: this old saying has inspired the work of the Organisation for Economic Co-operation and Development (OECD) for the past 75 years. The OECD collects comparative information on government policies in a variety of areas. In close collaboration with its member countries, it conducts comparative analysis of different policies to diagnose successes and failures, and crafts policy recommendations that help countries make better policies for better lives.

As part of its actitivies in the area of public governance, the OECD works with countries to improve their approaches to better regulation, often also referred to as regulatory policy. Regulatory policy is the key towards effective regulation. Together with taxation and spending programmes, regulation is one of government's key instruments to promote economic growth, enhance social welfare, ensure inclusiveness, protect the environment, respond to new technological challenges and increase the overall quality of life. Especially in times of disruptive technological change that transforms all facets of everyday life and economic activity, regulatory reform now more than ever represents a critical tool to ensure that regulation remains fit for purpose to drive innovation, and foster economic and social well-being. Regulatory policy covers the processes and institutions in place for designing, implementing and evaluating regulation to enhance their effectiveness and efficiency and ensure they are in the public interest. Regulatory policy is a truly horizontal policy, determining "the rules of rulemaking" that apply horizontally to all policy areas and sectors (OECD, 2018).

This article describes the OECD's efforts to develop a series of indicators on countries' regulatory policy practices and reflects on key features of these indicators that help foster better regulation among its member and partner countries. It outlines the development process for the OECD Indicators of Regulatory Policy and Governance (iREG) (section 2) and key design decisions made. Subsequently, it presents the latest indicator results to illustrate the type of analysis and diagnostics possible on the basis of the indicator design (section 3). After describing how the iREG indicators have been received and used in OECD countries and OECD policy analysis (section 4), the article concludes by reflecting on lessons learned from the OECD's experience in the development and use of the IREG indicators to drive international exchange on regulatory policy and regulatory reform (section 5).

\section{Designing the iREG indicators:} from principles to practices

In 2012, OECD countries adopted the OECD Recommendation on Regulatory Policy and Governance (OECD, 2012), the first international instrument to address regulatory policy, management and governance as a whole-of-government activity. The Recommendation sets out the measures that Governments can and should take to support the implementation and advancement of systemic regulatory reform to deliver regulations that meet public policy objectives and will have a positive impact on the economy and society. The measures cited in the Recommendation are integrated into a comprehensive policy cycle that connects the design of regulations to their implementation and evaluation, supported by enforcement mechanisms and appropriate institutions (see Box 1 for details).

When adopting the 2012 Recommendation, OECD countries committed to regularly monitor its implementation. To facilitate this monitoring process, the OECD launched the Regulatory Policy Outlook series. This series presents evidence-based analysis of the progress made in OECD member and partner countries in improving the way they regulate by implementing the principles outlined in the Recommendation. It also adopts a forward-looking perspective and sheds light on current trends and new challenges in the area of 


\section{BOX 1}

\section{OECD RECOMMENDATION OF THE COUNCIL ON REGULATORY POLICY AND GOVERNANCE}

- Commit at the highest political level to an explicit whole-of-government policy for regulatory quality. The policy should have clear objectives and frameworks for implementation to ensure that, if regulation is used, the economic, social and environmental benefits justify the costs, the distributional effects are considered and the net benefits are maximised.

- Adhere to principles of open government, including transparency and participation in the regulatory process to ensure that regulation serves the public interest and is informed by the legitimate needs of those interested in and affected by regulation. This includes providing meaningful opportunities (including on-line) for the public to contribute to the process of preparing draft regulatory proposals and to the quality of the supporting analysis. Governments should ensure that regulations are comprehensible and clear and that parties can easily understand their rights and obligations.

- Establish mechanisms and institutions to actively provide oversight of regulatory policy procedures and goals, support and implement regulatory policy, and thereby foster regulatory quality.

- Integrate Regulatory Impact Assessment into the early stages of the policy process for the formulation of new regulatory proposals. Clearly identify policy goals, and evaluate if regulation is necessary and how it can be most effective and efficient in achieving those goals. Consider means other than regulation and identify the trade-offs of the different approaches analysed to identify the best approach.

- Conduct systematic programme reviews of the stock of significant regulation against clearly defined policy goals, including consideration of costs and benefits, to ensure that regulations remain up to date, cost justified, cost effective and consistent, and deliver the intended policy objectives.

- Regularly publish reports on the performance of regulatory policy and reform programmes and the public authorities applying the regulations. Such reports should also include information on how regulatory tools such as RIA, public consultation practices and reviews of existing regulations are functioning in practice.

- Develop a consistent policy covering the role and functions of regulatory agencies in order to provide greater confidence that regulatory decisions are made on an objective, impartial and consistent basis, without conflict of interest, bias or improper influence.

- Ensure the effectiveness of systems for the review of the legality and procedural fairness of regulations and of decisions made by bodies empowered to issue regulatory sanctions. Ensure that citizens and businesses have access to these systems of review at reasonable cost and receive decisions in a timely manner.

- As appropriate apply risk assessment, risk management, and risk communication strategies to the design and implementation of regulations to ensure that regulation is targeted and effective. Regulators should assess how regulations will be given effect and should design responsive implementation and enforcement strategies.

- Where appropriate promote regulatory coherence through co-ordination mechanisms between the supranational, the national and sub-national levels of Government. Identify cross-cutting regulatory issues at all levels of Government, to promote coherence between regulatory approaches and avoid duplication or conflict of regulations.

- Foster the development of regulatory management capacity and performance at sub-national levels of Government.

- In developing regulatory measures, give consideration to all relevant international standards and frameworks for co-operation in the same field and, where appropriate, their likely effects on parties outside the jurisdiction.

SOURCE: OECD (2012). Recommendation of the Council on Regulatory Policy and Governance, Paris. OECD Publishing. 
regulatory policy to stimulate exchange and discussion among countries. The Outlook's inaugural edition was published in 2015 (OECD, 2015), followed by a second edition in 2018 (OECD, 2018). The Outlook series is planned to be published every three years.

The birth of the Recommendation and the Outlook series created a need for comprehensive evidence to monitor country practices. It also made apparent a large gap in the landscape of existing governance indicators -including e.g. the World Bank's Worldwide Governance and Doing Business Indicators (World Bank Group, 2019a, 2019b), the Bertelsmann Foundation's Sustainable Governance Indicators (Bertelsmann Stiftung, 2018), or the World Justice Project's Rule of Law Index (World Justice Project, n.d.)-, as at the time no organisation had produced comparative indicators covering in detail the processes and institutions in place for regulatory policy. Hence, the OECD decided to enter uncharted territory by creating its own indicator set to track developments in regulatory policy in its member countries over time. The OECD had previously collected information on countries' regulatory policy practices with the Regulatory Management Surveys, which were carried out in 1998, 2005 and 2008-2009 (OECD, 2009). The development of the iREG indicators built on this experience and improved its scope and methodology, building on the practices advocated in the 2012 Recommendation.

The resulting iREG indicators collect information on the content of regulatory policies, as well as on the requirements and practices of countries in three key areas of the 2012 Recommendation: stakeholder engagement for developing regulation, RIA and ex post evaluation of regulations. For most survey questions, answers are recorded separately for processes in place for primary laws that are adopted by Parliament or Congress, and for subordinate regulations that can be issued directly by the executive (OECD, 2018). In the following, we will describe the iREG indicator design process as well as their scope and limitations.

\section{Development of the iREG survey and composite indicators}

The OECD was faced with two major challenges when designing the iREG indicators: first of all, the indicators would need to operationalise the 2012 Recommendation's high-level policy principles into concrete and measurable indicators of requirements and practices. Secondly, the iREG would need to be able to capture diverse country practices and provide insights into how different countries approach similar regulatory policy requirements, including countries with advanced regulatory practices as well as efforts of countries that have recently started developing their regulatory policy, while simultaneously tracking country progress in a comparable manner over time.

To meet these needs and expectations, the OECD undertook extensive consultations with OECD country delegates. Delegates were consulted throughout the design process, ranging from the operationalisation of the Recommendation's principles to the design of the questionnaire, the data collection and verification, as well as analysis (for greater details see Annex II, Arndt, Baker, Querbach and Schultz, 2015). In particular, the OECD Secretariat relied heavily on comments and input from the OECD Steering Group on Measuring Regulatory Performance, an advisory group to the OECD Regulatory Policy Committee (RPC) that counsels the Committee on all projects regarding the measurement of regulatory performance ${ }^{1}$.

In a first step, delegates identified key practices for implementing the 2012 Recommendation at a series of meetings, including expert workshops in 2013 in Stockholm and in 2014 in The Hague (OECD, 2014 and OECD, 2013), as well as the biannual meetings of the OECD Regulatory Policy Committee in Paris. Based on the key practices identified, the OECD designed a

\footnotetext{
For further information on the OECD Programme on Measuring Regulatory Performance, please see http://www.oecd.org/gov/regulatorypolicy/measuring-regulatory-performance.htm
} 
questionnaire in consultation with the Steering Group on Measuring Regulatory Performance, and piloted the survey in several OECD countries.

The IREG data collection and verification methodology is also characterised by continued exchange with country delegates. Delegates to the OECD Regulatory Policy Committee and central government officials responded to the survey. Subsequently, survey answers underwent a thorough verification process in order to enhance data quality and ensure comparability of answers across countries and over time. This process was carried out by the OECD Secretariat in co-operation with delegates to the RPC. Preliminary country answers were reviewed by OECD analysts, checked for missing data and logical inconsistencies and presented to the RPC for feedback. As a result of the verification process, revisions to the survey answers were suggested where appropriate. The revised survey answers were submitted to country respondents for further comments on any adjustments and to provide missing answers and evidence before finalising the data.

Furthermore, the iREG survey was designed with a focus on evidence and examples to corroborate country responses. For questions on key requirements and practices, respondents were asked to provide reference documents such as legislation and guidance, or concrete examples of specific practices, e.g. documentation of stakeholder engagement conducted or examples of RIAs. This information was subsequently used to verify country responses and gain an understanding of the diverse country practices to implement formal requirements. Consequently, the iREG data is grounded in evidence not only of existing formal requirements in a country, but also of the concrete practices.

The iREG survey has been fielded twice. Data collections were carried out in 2014 and 2017 to feed into the OECD Regulatory Policy Outlook 2015 and 2018 editions. The information collected is fully comparable and allows for tracking countries' progress over time. For the 2017 data collection, minor adjustments to the indicator methodology were made in the area of stakeholder engagement (OECD, 2019c) to align the indicator framework with OECD countries' evolved thinking on the topic as presented in the OECD Best Practice Principles on stakeholder engagement (OECD, forthcoming, c). All adjustments were also made to the data for 2014 to ensure over-time comparability. In addition, the 2017 survey includes some new questions on international regulatory co-operation and a new section on regulatory oversight bodies. These extensions have formed the evidence base for new thematic chapters in the 2018 edition of the Regulatory Policy Outlook. These adjustments show that the IREG indicator framework can be adjusted and evolves in line with its normative basis for measurement.

Three composite indicators were constructed to summarise the information contained in the individual survey answers: one for RIA, one for stakeholder engagement and one for ex post evaluation (Arndt, Baker, Querbach and Schultz, 2015). The composite indicators were also constructed separately for practices covering primary laws and those covering subordinate regulations.

The methodology for the composite indicators draws on methodological best practice as well as design features identified with country delegates and experts. The design followed delegates' advice that indicators should be transparent and that score changes over time should reflect actual changes in a country's regulatory policy practices. Furthermore, the composite indicator design followed the recommendations provided in the 2008 OECD/JRC Handbook on Constructing Composite Indicators (OECD/EC/JRC, 2008).

Each composite indicator is composed of four equally weighted categories (Figure 1):

- Systematic adoption which records formal requirements and how often these requirements are conducted in practice;

- Methodology which gathers information on the methods used in each area, e.g. the type of impacts assessed or how frequently different forms of consultation are used; 


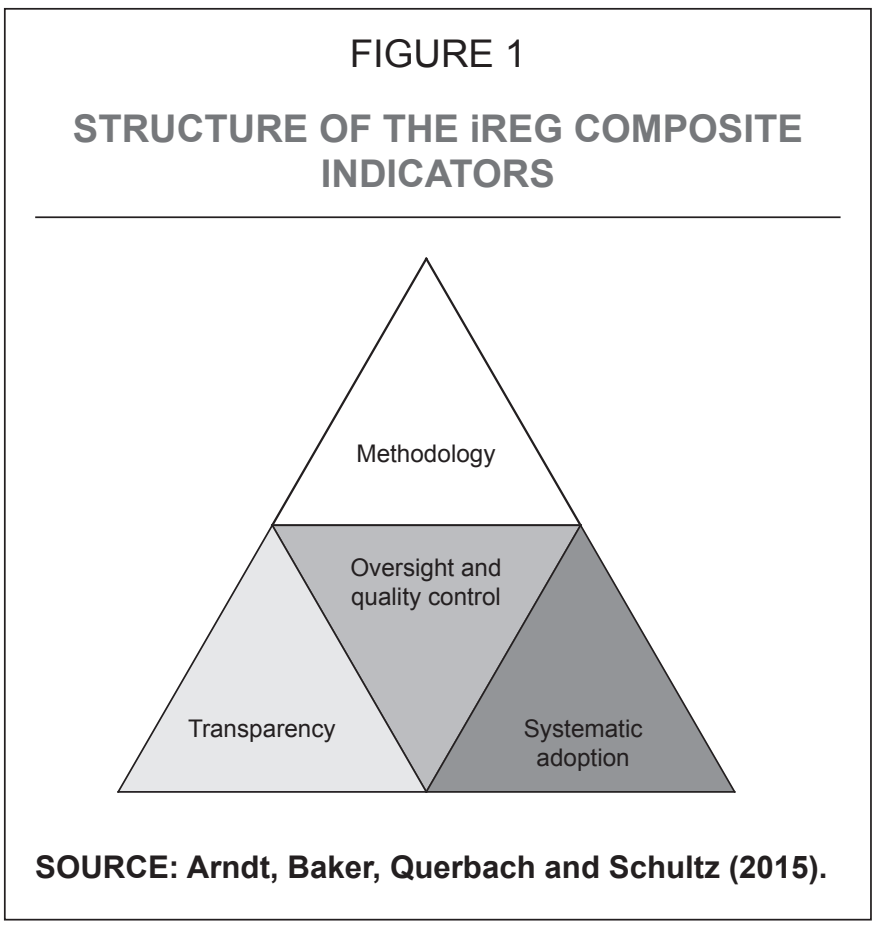

- Oversight and quality control records the role of oversight bodies and publically available evaluations; and

- Transparency which records information from the questions that relate to the principles of open government, e.g. whether Government decisions are made publically available.

Each category is composed of several equally weighted sub-categories built around specific questions in the iREG Survey.

To ensure full transparency, the iREG data as well as all documentation regarding the survey, the methodology for constructing the composite indicators, results of the sensitivity analysis to different methodological choices and results from the analysis based on the iREG data is publicly available on the OECD website (http://oe.cd/ireg).

\section{Scope and limitations of iREG}

The iREG indicators focus on the processes of developing regulations that are carried out by the executive branch of the national Government and that apply to all policy areas. This means that processes in place for laws initiated by Parliament are not covered. The exception are the indicators on ex post evaluation, which cover all national regulations regardless of whether they were initiated by Parliament or the executive. Based on available information, most national regulations in the countries surveyed are covered by the IREG survey, with some variation across countries. Most countries covered by iREG have parliamentary systems, i.e. the majority of their national primary laws originate from initiatives of the executive. This is not the case, however, for the United States where no primary laws are initiated by the executive, or, to a lesser extent, for Colombia, Costa Rica, Korea and Mexico where a majority of primary laws are initiated by the legislature (OECD, 2018).

In interpreting the iREG indicator results, it is important to bear in mind the methodological limitations of composite indicators $(i b d$.$) . Composite indicators are useful in$ their ability to integrate large amounts of information into an easily understood format (Freudenberg, 2003). However, given their nature, cross-country comparable indicators cannot be context specific and fully capture the complex realities of the quality, use and impact of regulatory policy given the wide range of governance structures, administrative cultures and institutional and constitutional settings of OECD countries (OECD, 2018).

In-depth country reviews are therefore required to complement the indicators. Reviews can provide a detailed analysis of the content, strengths and shortcomings of countries' regulatory policies, as well as detailed and context-specific recommendations for improvement. It is also important to bear in mind that the indicators should not be interpreted as a measurement of the quality of regulation itself. While the implementation of the measures assessed by the indicators aim to deliver regulations that meet public policy objectives and will have a positive impact on the economy and society, the indicators themselves do not assess the achievement of these objectives. Finally, the results of composite indicators are always sensitive to methodological choices. It is 
therefore not advisable to make statements about the relative performance of countries with similar scores. Instead, composite indicators should be seen as a means of initiating discussion and stimulating public interest (OECD/EC/JRC, 2008).

\section{What iREG can tell us - Results from the 2018 OECD Regulatory Policy Outlook}

This section presents the latest results from the OECD IREG indicators. It draws largely on the OECD Regulatory Policy Outlook 2018 (OECD, 2018). Results are presented for the areas of stakeholder engagement, RIA and the ex post evaluation of regulation, as well as separately for practices in place for primary laws and for subordinate regulations. The data cover two points in time: as of 31 December 2014 and 31 December 2017. Data for 2014 cover 34 OECD member countries as well as the European Union, while data for 2017 cover all 38 OECD member and accession countries and the European Union. More detailed results, specific examples of country practices as well as individual country profiles outlining latest reforms, successes and recommendations for further improvement can be found in OECD, 2018. In addition to the analysis conducted in the Regulatory Policy Outlook series, an OECD Working Paper analyses how countries put in place different building blocks of their regulatory policy systems and identifies country groupings on the basis of the iREG indicators (Arndt, Hermanutz, Kauffmann and Schultz, 2016).

Overall, the iREG results show that OECD countries are committed to regulatory policy. Most countries have adopted an explicit regulatory policy and assigned a high-level official with responsibility for regulatory reform. A majority of countries surveyed have also adopted broad requirements and developed some form of methodology for conducting stakeholder engagement and RIA.

The iREG indicators also uncover key gaps in countries' current practices. Strikingly, OECD countries have invested much less in the ex post evaluation of regulations than in good regulatory practices during the regulatory design phase. Furthermore, oversight and quality control is the area where most OECD countries still have a lot to improve across all three tools examined by iREG. This finding is in line with other research that points to oversight as a critical factor for establishing regulatory management tools that function over the long term (Ladegaard, Lundkvist and Kamkhaji, 2018). Oversight mechanisms can help bridge the gap between formal requirements and their implementation in practice, and ensure that regulatory policy is used in the best public interest.

The following sub-sections present key findings on each of the three areas covered by the iREG indicators.

\section{Stakeholder engagement in developing regulations}

Stakeholder engagement is an essential step in the design of new regulations (OECD, forthcoming, c). Consulting with those concerned by regulations, i.e. citizens, businesses, civil society and other actors, ensures that regulations are in the best public interest. Stakeholders provide valuable insights and experience about the problems to be solved and possible means to address them. Stakeholder engagement also ensures that regulations are inclusive, involving all parties affected by a new regulation. Finally, stakeholder engagement helps those affected to develop a sense of ownership of the regulatory framework. This in turn strengthens trust in Government, social cohesion and compliance with regulations.

Results from the OECD Regulatory Policy Outlook 2018 (OECD, 2018) (Figures 2 and 3 ) show that OECD countries are overall committed to consult with stakeholders when developing new regulations. All OECD member and accession countries have systematically adopted requirements to engage with stakeholders during the regulatory design phase. In many countries, however, requirements are more strict for practices regarding primary laws than those regarding subordinate regulations. Members of the public can participate in 
FIGURE 2

\section{OECD IREG COMPOSITE INDICATORS: STAKEHOLDER ENGAGEMENT IN DEVELOPING PRIMARY LAWS, 2018}

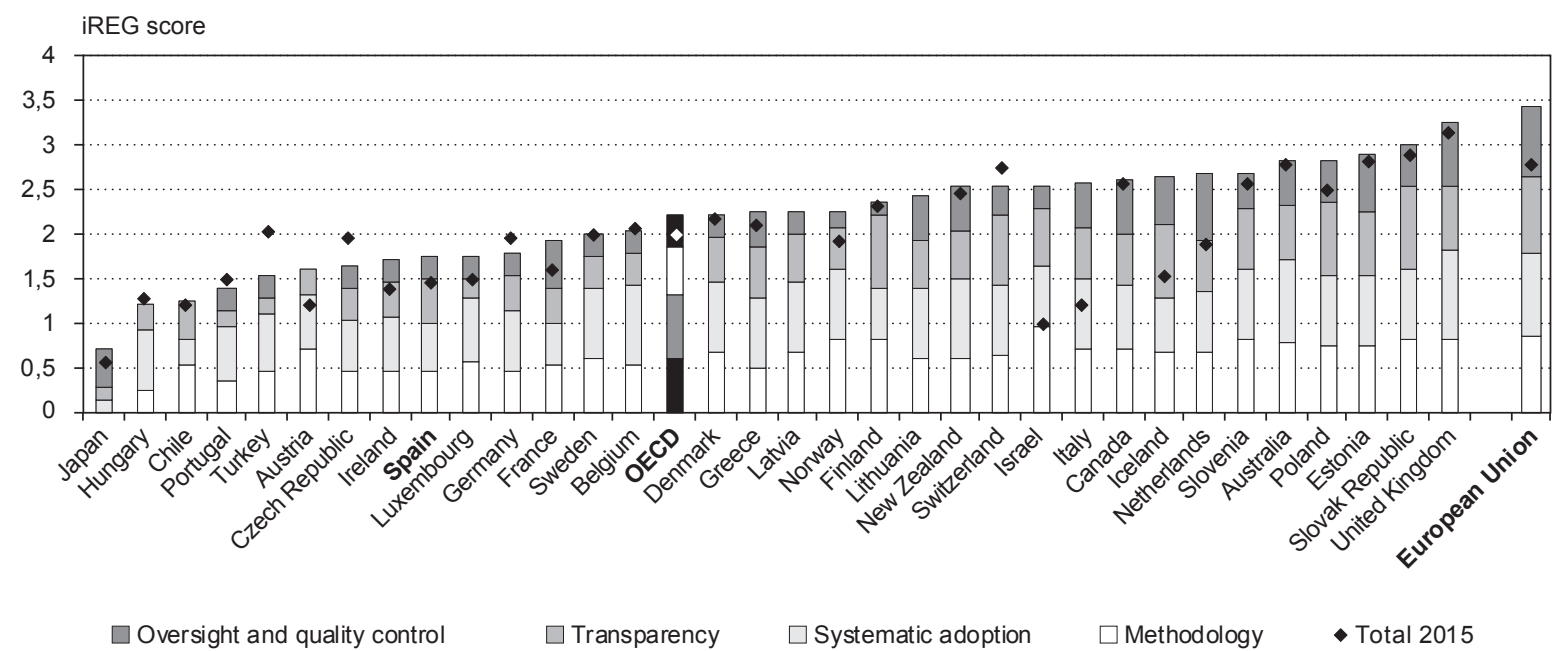

NOTES: Data for OECD countries is based on the 34 countries that were OECD members in 2014 and the European Union. Data on the new OECD member and accession countries Colombia, Costa Rica, Latvia and Lithuania is only available for 2017 . The more regulatory practices as advocated in the 2012 Recommendation a country has implemented, the higher its iREG score. The indicator only covers practices in the executive. This figure therefore excludes the United States where all primary laws are initiated by Congress, as well as Colombia, Costa Rica, Korea and Mexico, where a majority of primary laws are initiated by the legislature.

SOURCE: Indicators of Regulatory Policy and Governance Surveys 2014 and 2017, http://oe.cd/ireg

consultations during the development of at least some regulations through various forms of stakeholder engagement, such as physical or virtual public meetings, public consultations over the internet or informal consultations.

While OECD countries have invested in stakeholder engagement methodologies, there is still a lot of room for improvement regarding the accessibility and timing of consultations. Most forms of stakeholder engagement happen at a late stage in the development process once a draft regulation has been prepared. OECD Governments engage far less systematically with stakeholders at an early stage in the policy process to inform officials about the policy problem to be solved and potential solutions. Hence, useful input from stakeholders can only be considered at a late stage once a decision on how to solve a policy problem has already been identified. Many Governments could still broaden the scope of their consultations. They only consult with the broader public on selected laws and regulations, or they reach out exclusively to selected stakeholders through informal outreach or formal consultations. Broadening consultation practices to a greater range of stakeholders and covering more draft regulations can help ensure that all of those concerned can voice their thoughts on new regulatory projects and that Governments do not just listen to some selected few.

There is great potential for most OECD countries to improve the transparency of their stakeholder engagement practices. For example, only about two thirds of OECD countries have a mechanism in place to inform 
FIGURE 3

\section{OECD IREG COMPOSITE INDICATORS: STAKEHOLDER ENGAGEMENT IN DEVELOPING SUBORDINATE REGULATIONS, 2018}

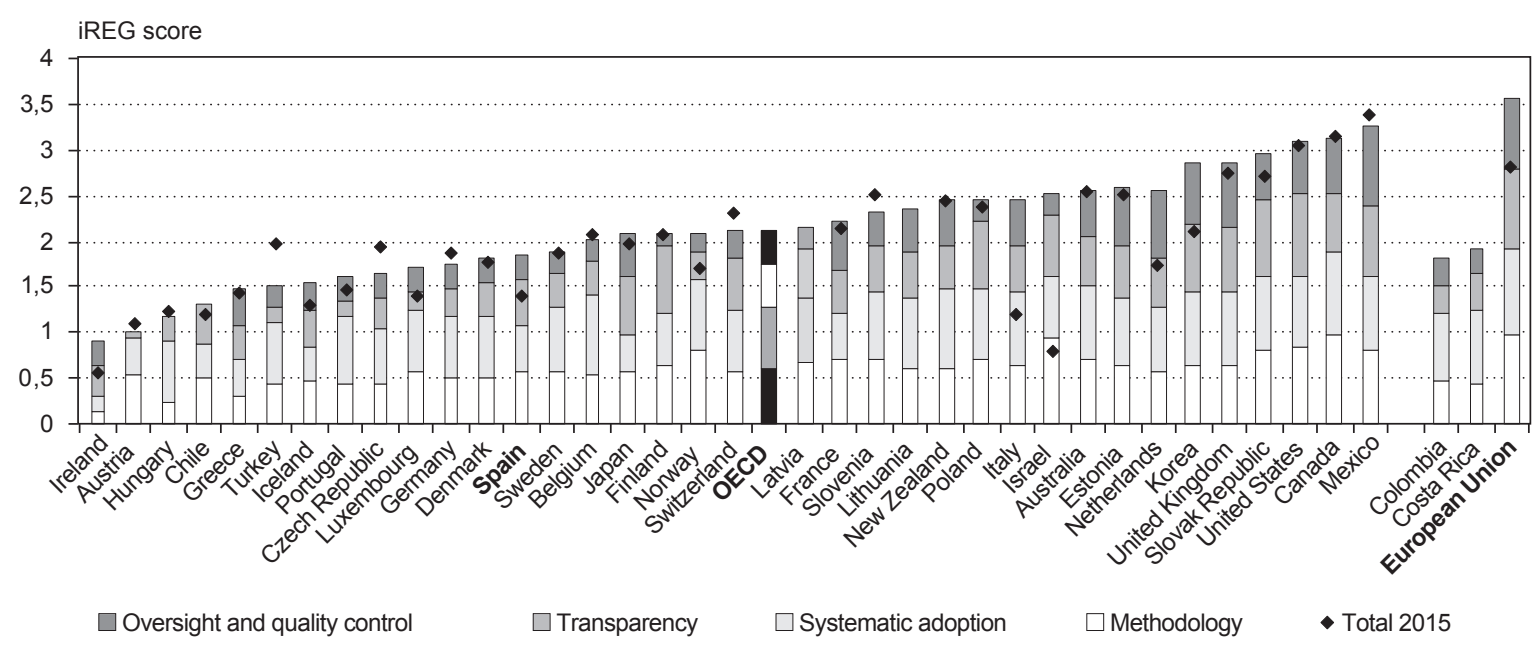

NOTES: Data for OECD countries is based on the 34 countries that were OECD members in 2014 and the European Union. Data on the new OECD member and accession countries Colombia, Costa Rica, Latvia and Lithuania is only available for 2017. The more regulatory practices as advocated in the 2012 Recommendation a country has implemented, the higher its iREG score.

SOURCE: Indicators of Regulatory Policy and Governance Surveys 2014 and 2017, http://oe.cd/ireg

stakeholders in advance about upcoming consultations, so they can plan and prepare their input. Furthermore, while most OECD countries publish consultation comments received online and pass on the views of stakeholders to political decision-makers, only about a quarter of them require that regulators provide feedback to participating stakeholders on how their comments have been taken into account in the regulatory process.

Finally, oversight and quality control of stakeholder engagement remains the weakest area covered by the iREG indicators in a majority of OECD countries. Only a few countries have in place a quality control system for stakeholder engagement, such as an oversight body that checks whether consultations have been carried out in an adequate and inclusive manner. So far, only a handful of OECD jurisdictions regularly evaluates the functioning of their stakeholder engagement systems. Greater evaluation efforts could help countries identify common problems and gaps in their consultation practices to inform future reforms.

OECD countries have only made slight improvements in their stakeholder engagement practices between 2014 and 2017, although some countries have made substantial reforms. Greater progress has been made with regard to practices for primary laws than with regard to subordinate regulations. In particular, a number of countries have extended the requirements and practice of their stakeholder engagement efforts, for example by conducting consultations on a more systematic basis early in the regulatory development process or by opening up more consultations to the general public. For example, Iceland and the 


\section{FIGURE 4}

\section{OECD IREG COMPOSITE INDICATORS: REGULATORY IMPACT ASSESSMENT FOR DEVELOPING PRIMARY LAWS, 2018}

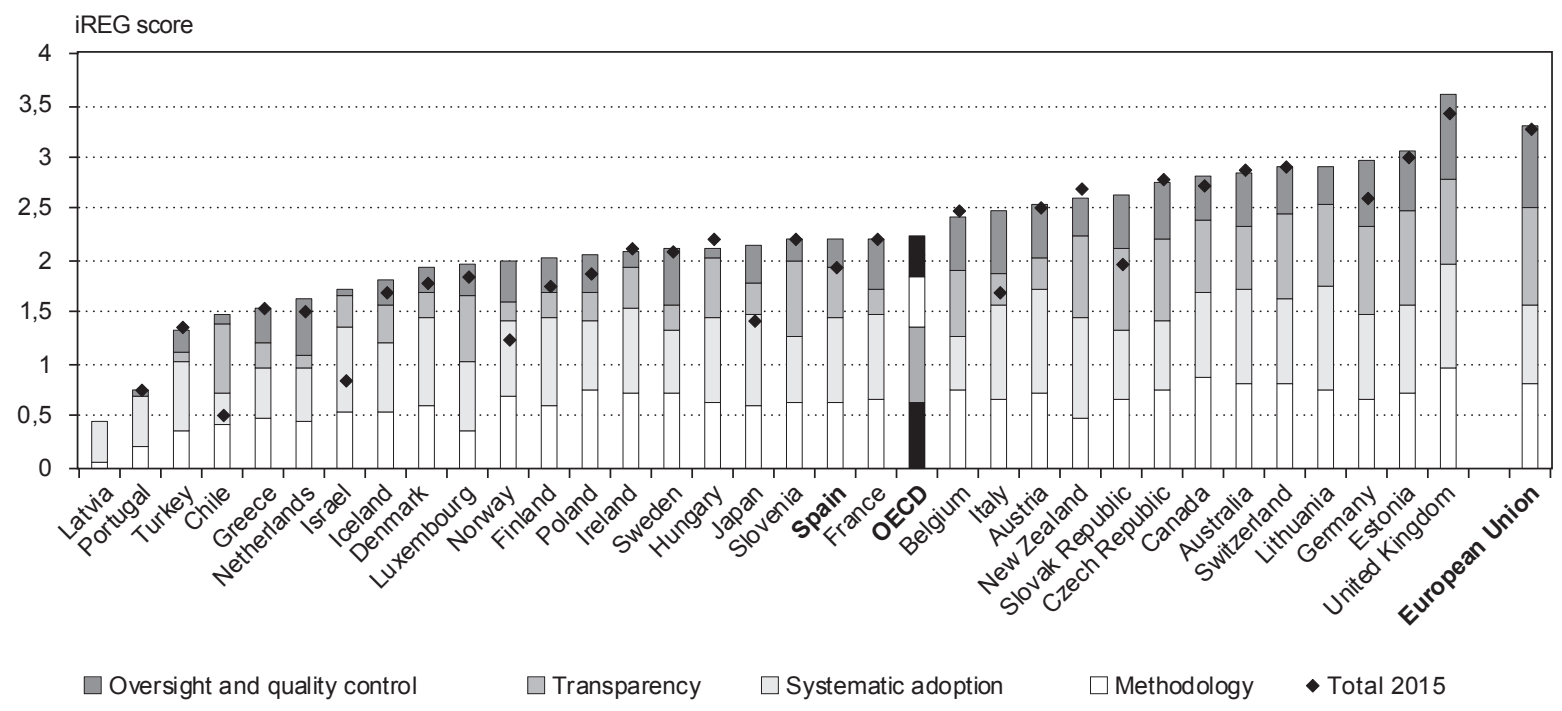

NOTES: Data for OECD countries is based on the 34 countries that were OECD members in 2014 and the European Union. Data on the new OECD member and accession countries Colombia, Costa Rica, Latvia and Lithuania is only available for 2017 . The more regulatory practices as advocated in the 2012 Recommendation a country has implemented, the higher its iREG score. The indicator only covers practices in the executive. This figure therefore excludes the United States where all primary laws are initiated by Congress, as well as Colombia, Costa Rica, Korea and Mexico, where a majority of primary laws are initiated by the legislature.

SOURCE: Indicators of Regulatory Policy and Governance Surveys 2014 and 2017, http://oe.cd/ireg

European Commission have recently introduced reforms to broaden the scope of stakeholder engagement at different stages of the regulatory development process.

\section{Regulatory Impact Assessment}

RIA supports policy makers' decision on whether and how to regulate $(O E C D$, forthcoming, a). It analyses the costs and benefits of regulation and non-regulatory alternatives of achieving policy goals to identify the most efficient and effective solution to address a policy problem. RIA also unveils the trade-offs to be made in regulatory decisions and points to those that are likely to gain from a regulation and those likely to lose out. RIA helps avoid regulatory failure, which may arise from unnecessary regulation, or failing to regulate when regulation is needed. Finally, RIA is an important instrument to increase Government accountability, as it documents the evidence underlying policy decisions.

Most OECD member and accession countries have embraced the concept of RIA, although implementation in practice frequently lags behind countries' formal commitments (Figures 4 and 5). Almost all countries covered in iREG have adopted a requirement for some form of RIA. RIA requirements are usually less stringent for the development of primary laws than the development of subordinate regulations. Even where RIA is required it is not always conducted in practice, although this implementation gap has been closing gradually since 2014 . Furthermore, about a third of OECD countries has rules that exempt certain regulations from RIA, and only few 


\section{FIGURE 5}

\section{OECD IREG COMPOSITE INDICATORS: REGULATORY IMPACT ASSESSMENT FOR DEVELOPING SUBORDINATE REGULATIONS, 2018}

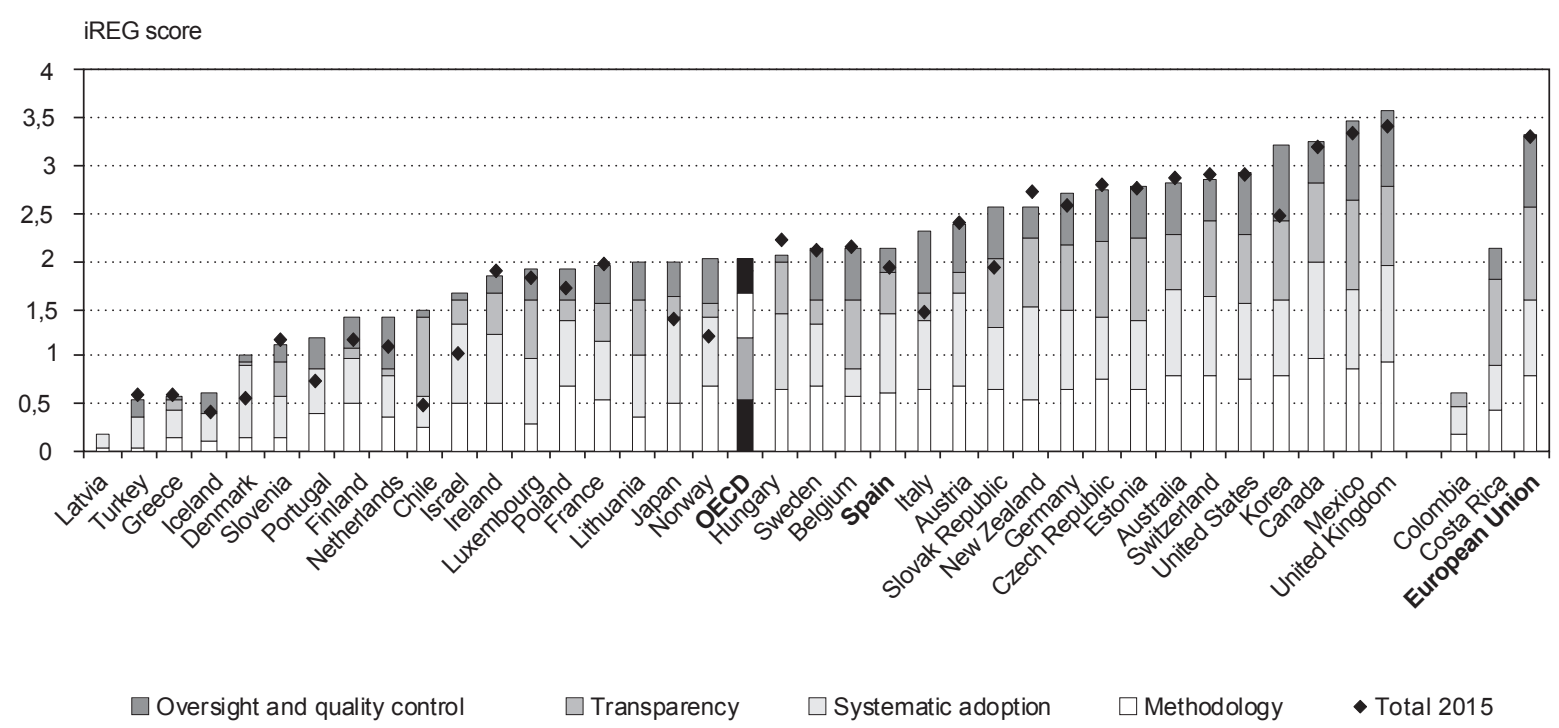

NOTES: Data for OECD countries is based on the 34 countries that were OECD members in 2014 and the European Union. Data on the new OECD member and accession countries Colombia, Costa Rica, Latvia and Lithuania is only available for 2017. The more regulatory practices as advocated in the 2012 Recommendation a country has implemented, the higher its iREG score.

SOURCE: Indicators of Regulatory Policy and Governance Surveys 2014 and 2017, http://oe.cd/ireg

countries have put in place mechanisms to compensate for a lack of RIA, such as a post-implementation review of the regulation's impacts.

The breadth and scope of RIA methodologies vary significantly among countries, notably regarding the depth of analysis and the variety of impacts assessed. While assessment efforts should be proportionate to the significance of a regulatory proposal, regulators should ensure that all relevant impacts are investigated to gain full understanding of the regulation's overall effect and aim at analysing in detail those impacts that will be particularly significant. Many OECD countries now require regulators to assess both the costs as well as the benefits of a regulatory proposal. However, the quantification of benefits still lags behind the quantification of costs. In addition, economic impacts such as on competition or small businesses are more frequently assessed than social or distributional impacts of regulation.

Most countries with high iREG scores in the area of RIA have invested in the transparency and oversight of their RIA system. This means that they do not only publish RIAs, but release draft RIAs publicly for comments to integrate stakeholder feedback that may help close data gaps or correct faulty assumptions in the analysis. In the area of oversight, many countries can still strengthen the institutional mechanisms for verifying the quality of draft RIAs. Most OECD member and accession countries have established an oversight body that reviews the quality of draft RIAs, and new oversight bodies have been created in several countries, such as the Better Regulation Councils of Finland and Norway, or the Spanish Office of Regulatory Coordination and Quality. However, 
only about a third of those bodies can return the RIA for revisions in case its quality is deemed inadequate.

OECD countries have been stalling in the area of RIA between 2014 and 2017, despite the fact that a few countries have implemented significant reforms. Improvements have been greater for RIA practices for subordinate regulations than for primary laws, which is in part owing to the fact that RIA practices are overall less elaborated for subordinate regulations. Most recent reforms have supported the systematic adoption of RIA by extending requirements and application in practice. Many countries have also recalibrated their RIA approaches to be more proportionate. For example, a range of countries, including Japan and Korea, has introduced a threshold test to determine whether a full RIA or a simplified version is to be carried out.

\section{Ex post evaluation of regulations}

In view of today's constant societal and technological changes, Governments need to regularly review their regulations to verify if they are still fit for purpose. Even the most well-designed regulations may become outdated over time or may have unintended effects, costs or benefits once implemented in practice. Laws and regulations that are (no longer) fit for purpose generate unnecessary regulatory burden that complicates the life of citizens and the efficient operation of businesses. Ex post evaluations of regulations do not only uncover such problems, but also deliver important insights for improving new regulations and thus create a feedback loop into regulatory planning and design. They also increase trust in Government by giving account to citizens and business of how well regulations function (OECD, forthcoming, b).

Despite the great importance of ex post evaluation, OECD countries overall make few efforts to evaluate their existing regulations (Figures 6 and 7). This is particularly striking in comparison to the much greater investments countries have made to develop their approaches to assess and consult on new regulations.
This failure to close the regulatory policy cycle by feeding evaluation results back into the regulatory design process is manifest both for processes in place for primary laws as well as subordinate regulations.

Most OECD countries have not developed a systematic approach to ex post evaluation. Only about two thirds of the OECD membership require that laws and regulations are evaluated periodically, and in most cases these requirements only apply to some regulations. In a similar vein, a majority of countries do not have a standard methodology for conducting ex post evaluations. Notably, only about half of all countries surveyed in $\mathrm{iREG}$ assess whether a regulation has achieved its policy goals when carrying out ex post evaluation. In contrast, a great number of OECD countries has conducted ad hoc reviews of the existing stock of regulations. These reviews most frequently screen regulations for the administrative burden they create with the aim to reduce these burdens. Other types of reviews to evaluate the stock of existing regulation are much less frequent. For example, only 15 out of 38 countries surveyed have conducted in-depth reviews, i.e. comprehensive reviews that focus on the nature, extent and cumulative impact of regulation in specific industries, policy areas or sectors.

Transparency is the area where OECD countries score highest. This means that when countries conduct ex post evaluations, they frequently make at least some of the results publicly available and have established mechanisms for stakeholders to provide feedback on existing regulations, such as electronic mailboxes or petitions for reconsideration.

As for stakeholder engagement and RIA, oversight and quality control is very weak in the area of ex post evaluation. Most OECD countries have not established a system for verifying the quality of ex post evaluations, which may be linked to the fact that most countries do not systematically conduct ex post evaluations in the first place. Only nine OECD countries have published a performance report on the functioning of their ex post evaluation system. Countries could greatly 


\section{FIGURE 6}

\section{OECD IREG COMPOSITE INDICATORS: EX POST EVALUATION FOR PRIMARY LAWS, 2018}

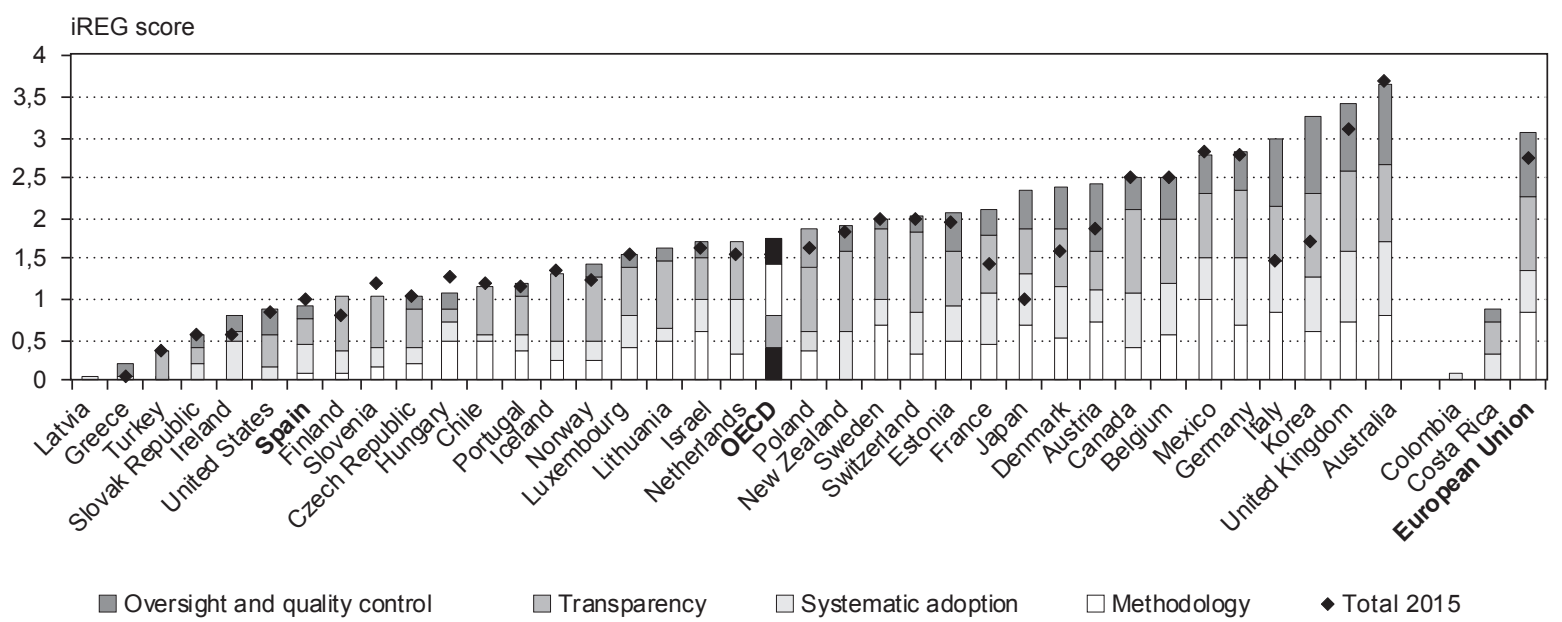

NOTES: Data for OECD countries is based on the 34 countries that were OECD members in 2014 and the European Union. Data on the new OECD member and accession countries Colombia, Costa Rica, Latvia and Lithuania is only available for 2017. The more regulatory practices as advocated in the 2012 Recommendation a country has implemented, the higher its iREG score.

SOURCE: Indicators of Regulatory Policy and Governance Surveys 2014 and 2017, http://oe.cd/ireg

\section{FIGURE 7}

OECD IREG COMPOSITE INDICATORS: EX POST EVALUATION FOR SUBORDINATE REGULATIONS, 2018

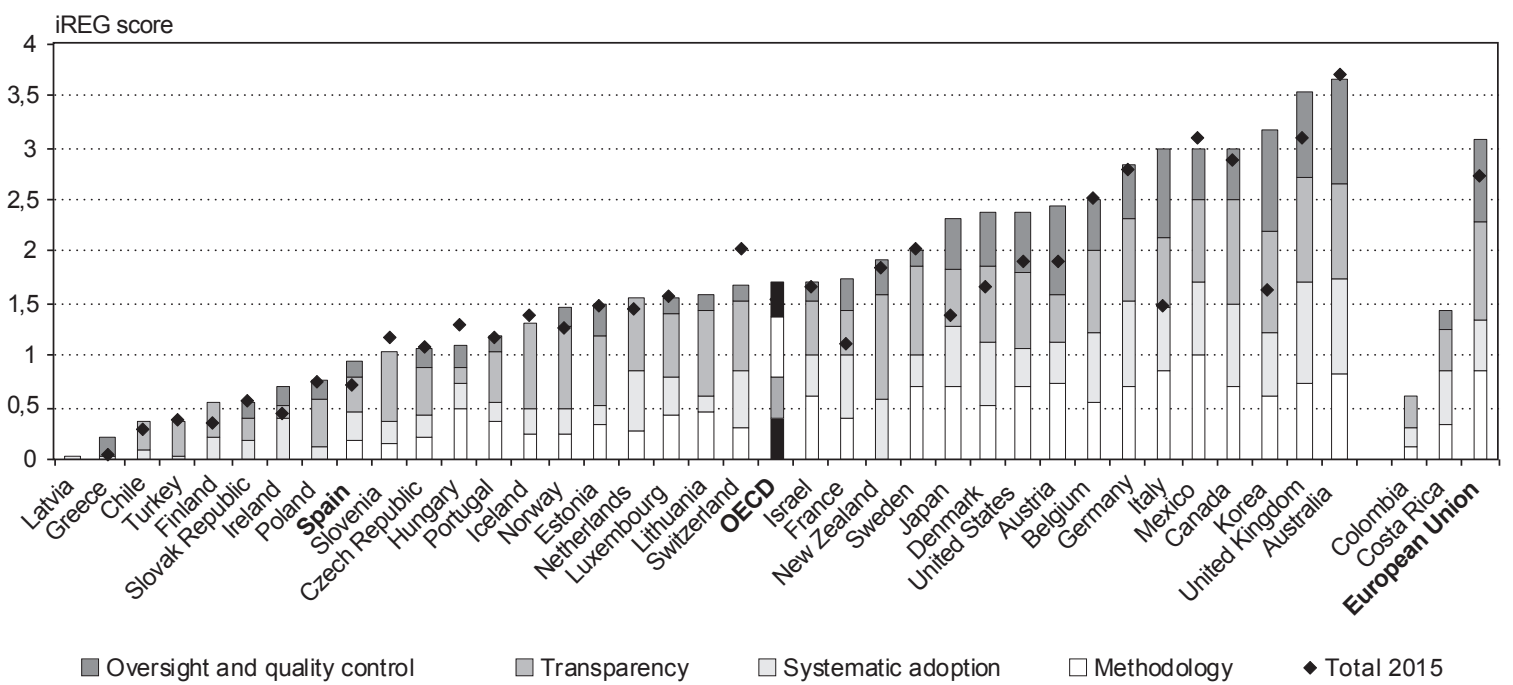

NOTES: Data for OECD countries is based on the 34 countries that were OECD members in 2014 and the European Union. Data on the new OECD member and accession countries Colombia, Costa Rica, Latvia and Lithuania is only available for 2017 . The more regulatory practices as advocated in the 2012 Recommendation a country has implemented, the higher its iREG score.

SOURCE: Indicators of Regulatory Policy and Governance Surveys 2014 and 2017, http://oe.cd/ireg 
benefit from regularly reviewing their approach to ex post evaluation to identify progress and gaps, and from establishing a dedicated body or unit that is responsible for checking the quality of ex post evaluations.

OECD countries have overall made only very small improvements to their ex post evaluation systems in the past three years. Some countries, however, have carried out greater reform efforts: for example, Italy and Japan have introduced new procedures and proportionality requirements for conducting ex post evaluations. Other countries have introduced new mechanisms for managing the stock of their regulations. The Danish Business Forum conducts in-depth reviews in different policy areas, and various countries, including Germany, Spain and the United States, have introduced new stock-management approaches to offset regulatory costs (Trnka and Thuerer, 2019).

\section{How has iREG been used?}

Following its first publication in 2015, the iREG indicators have become a core tool and one of the world's leading governance indicators tracking countries' progress in implementing regulatory policy. This section provides a brief overview of how iREG has been received and used by countries as well as within the OECD.

The publication of the iREG indicators has stimulated reforms of better regulation approaches in various countries, and has initiated closer co-operation on regulatory reform between the OECD Secretariat and some of its members. For example, the 2015 iREG results have been a key driver to promote regulatory reforms in Norway, including the establishment of a new body for regulatory oversight (Regelrådet, 2016). Both Israel and Portugal have been engaging in new co-operation projects with the OECD to improve their regulatory policy framework following the release of iREG. In Israel, the OECD evaluated key regulatory policy reforms introduced in 2014. The evaluation concluded that Israel conducted significant efforts to improve better regulation, and made several policy recommendations to further improve regulatory policy in Israel over the short and long term (Solomon, 2018). Portugal has implemented a series of reforms to their RIA system since 2017 . The OECD has been supporting this process since 2017 through a review of RIA practices in Portugal and the development of policy advice for further reforms, as well as through several capacity-building workshops (OECD, 2019d).

There has been continuous demand to broaden the coverage of IREG and extend its underlying dataset. While the iREG's first edition of 2015 covered the then 34 OECD member countries and the European Union, the 2018 edition extended the coverage to all 38 OECD member and accession countries and the European Union. In addition, an abbreviated version of the iREG data collection was carried out in seven Latin American countries in 2016 in collaboration with the Inter-American Development Bank to map these countries' efforts to develop and evaluate their regulations. Key results were published in OECD Government at a Glance: Latin America and the Caribbean 2017 (OECD, 2016), as well as more in-depth analysis in an OECD Working Paper (Querbach and Arndt, 2017). Recently, the OECD extended the iREG indicators to cover all Member States of the European Union, including those countries that are not members of the OECD. A forthcoming associated report assesses all EU Member States' and the European Union's domestic practices in the area of stakeholder engagement, RIA and ex post evaluation of regulation, as well as the use of regulatory management tools by EU countries when developing and implementing EU legislative acts (OECD, 2019a).

The iREG indicators are also an integral part of a range of OECD flagship products and publications on public governance, well-being and sustainable development. This reflects a general recognition of the importance of sound regulatory policies to achieve high-priority economic and social goals. The iREG composite indicator for stakeholder engagement is one of two core measures for the dimension "civic 
engagement" of the OECD Better Life Index. The Better Life Index maps country performance in 11 areas considered essential for well-being, including material living conditions and different aspects of the quality of life (OECD, 2019b). iREG is furthermore included in the OECD's framework to assess OECD countries' progress in implementing the United Nations Sustainable Development Goals. In particular, iREG is used to measure the implementation of Goal 16 on "Peace, Justice and Strong Institutions" by developing "effective, accountable and transparent institutions at all levels" (sub-goal 16.6) and ensuring "responsive, inclusive, participatory and representative decision-making at all levels" (sub-goal 16.7) (OECD, 2017b). Finally, key results from iREG are regularly presented in a chapter on regulatory governance in Government at a Glance, the OECD's flagship series on public governance that provides key data and a snapshot of current trends in OECD countries for various aspects of public governance (OECD, 2017a; OECD, 2015b).

\section{Conclusion - Lessons learned from the iREG experience}

What can the OECD's experience in developing the iREG indicators tell us about the kind of regulatory indicators that are most useful for policy makers and help create impact? We believe that five critical success factors led to the success of iREG: actionability, communication and peer learning, transparency, investment in design, and awareness of the inherent limitations of all governance indicators.

First of all, from the outset the iREG indicators were designed to help countries improve their better regulation efforts. They are an actionable tool that tracks countries' progress in implementing good regulatory practices over time. iREG provides countries with an opportunity to take stock of their current practices, monitor developments over time and identify potential areas for reform and improvement. In that context, it proved essential to ground iREG in the 2012
Recommendation, a normative framework for regulatory policy that had been jointly developed and adopted by all participating countries and thus provided a common starting point for countries and the OECD Secretariat to develop the indicators. Furthermore, the advisory role of country delegates, and in particular the OECD Steering Group on Measuring Regulatory Performance, cannot be underestimated. Their comments ensured that the indicators were designed to be policy-relevant and not overly complicated, so that users could easily distil policy messages from the indicator results. Vice versa, the iREG indicators have also created a feedback loop into the OECD Regulatory Policy Committee's normative work. They clearly show current trends in regulatory policy, but also uncover common gaps and challenges, which has prompted RPC delegates to discuss possible ways to overcome them. Results of these discussions have in turn been taken into account for developing the OECD Best Practice Principles series (OECD, forthcoming a, b, c).

Secondly, the iREG indicators are an essential communication as much as a measurement tool. The iREG composite indicators provide a useful snapshot of regulatory policy in a given country, and - given their actionable nature - point to recent reforms and successes while alerting policy makers to existing gaps in the regulatory policy framework. Thus, they fill an existing void and generate interest in better regulation, a topic which is often neglected by both political decision makers and the broader public. Anecdotal evidence has shown that such enhanced interest by political decision makers, stakeholders and the media helps generate momentum for reforms and greater use of regulatory policy tools. In addition, the iREG design process was a valuable peer learning exercise. OECD country delegates, and in particular members of the Steering Group on Measuring Regulatory Performance, were involved throughout the process from the design of the survey and composite indicators to the data collection, verification and the discussion of results. Delegates from countries with very diverse regulatory systems 
engaged in constructive deliberation to identify common ground and core (measurable) aspects of good regulatory practices rather than emphasising differences. This process bred a feeling of ownership of the iREG indicators and created the necessary buy-in for their publication and use in countries. It also enabled countries to exchange on and be inspired by different ways to implement the identified core practices. As a recent academic analysis of the IREG development process put it: "The OECD process was one of self-directed learning fulled by high socialization, internal validation of knowledge, favorable attitudes and posture of the Secretariat, and mutually constitutive roles of delegates and staff" (Radaelli, 2018).

Thirdly, the iREG's actionability and value as a communication tool are enhanced through transparency of process and results. Information on the IREG design process, the survey questions, the methodology to collect data and compile the composite indicator scores, as well as all individual country answers and composite scores are available free of charge on the OECD website (http://oe.cd/ireg). This enables policy makers and others, for example in academic or civil society, to understand what iREG measures and how. Furthermore, the wealth of data generated by IREG can be used for further analysis and research to improve the overall understanding of regulatory reforms.

Furthermore, the IREG experience has also shown that an investment into sound indicator design pays off. It took almost two years between 2013 and 2015 to operationalise the 2012 Recommendation's principles, design the iREG survey, collect and validate the data and develop the iREG composite indicators. Deliberation with OECD delegates at various stages in the process, piloting the survey tool, engaging in an extensive data collection and verification process with country respondents and testing the robustness of the composite indicator design all required significant amounts of time and resources. As a result, however, the iREG indicators are firmly grounded in a commonly agreed normative framework, capture a variety of diverging better regulation practices, and data quality is high. These features ensure that iREG is a credible, useable and relevant tool for countries.

Finally, despite its success the iREG indicators are not a panacea for improving better regulation in OECD countries. It is important to bear in mind their inherent limitations as a policy tool. They cover certain core aspects of regulatory policy, but leave out others. They provide a useful snapshot of stakeholder engagement, RIA and ex post evaluation requirements and practices, but they cannot fully capture the complex realities of the quality, use and impact of regulatory policy. Finally, by their very nature as cross-country indicators, they do not capture country- and context-specific details of the regulatory system. Communicating openly these limitations is essential to ensure that the iREG results are not misinterpreted or misused.

To conclude, the OECD iREG indicators have filled a gap in the landscape of governance indicators. They have sparked interest and exchange on the importance of better regulation and provide a diagnostic tool for countries that helps identify areas for improvement. As such, they can provide an important impetus for more in-depth analysis of a country's regulatory policy to complement insights from the indicators, catalyse reforms, and ultimately help create better policies for better lives.

\section{Bibliographic references}

Arndt, C., Baker, A. C., Querbach, T. and Schultz, R. (2015). 2015 Indicators of Regulatory Policy and Governance: Design, Methodology and Key Results. OECD Regulatory Policy Working Papers, (1), OECD Publishing, Paris.

Arndt, C., Hermanutz, S., Kauffmann, C. and Schultz, R. (2016). Building Regulatory Policy Systems in OECD Countries. OECD Regulatory Policy Working Papers, (5), OECD Publishing, Paris.

Bertelsmann Stiftung (2018). Sustainable Governance Indicators. http://www.sgi-network.org/2018/, last accessed 13 February 2019.

Freudenberg, M. (2003). Composite Indicators of Country Performance: A Critical Assessment. OECD Science, Technology and Industry Working Papers, (16). OECD Publishing, Paris. 
Ladegaard, P., Lundkvist, P. and Kamkhaji, J. (2018). Giving Sisyphus a Helping Hand. Pathways for Sustainable RIA Systems in Developing Countries. World Bank Policy Research Working Paper (8.467), World Bank Group, Washington DC.

OECD (2009). Indicators of Regulatory Management Systems. OECD Publishing, Paris.

OECD (2012). Recommendation of the Council on Regulatory Policy and Governance. OECD Publishing, Paris. http://www. oecd.org/gov/regulatory-policy/2012-recommendation.htm

OECD (2013). Assessing Progress in the Implementation of the 2012 Recommendation of the OECD Council on Regulatory Policy and Governance. Policy Findings and Workshop Proceedings, 5th Expert Meeting on Measuring Regulatory Performance. OECD, Paris, www.oecd.org/regreform/regulatory-policy/proceedings-sweden-workshop.pdf.

OECD (2014). Evaluating Stakeholder Engagement in Regulatory Policy. Policy Findings and Workshop Proceedings, 6th Expert Meeting on Measuring Regulatory Performance. OECD, Paris, www.oecd.org/gov/regulatory-policy/workshop-proceedings-mrp-the-hague.pdf, last accessed 13 February 2019.

OECD (2015). 2015 Regulatory Policy Outlook, OECD Publishing, Paris. http://www.oecd.org/gov/oecd-regulatory-policy-outlook-2015-9789264238770-en.htm

OECD (2015b). Government at a Glance 2015. OECD Publishing, Paris.

OECD (2016). Government at a Glance: Latin America and the Caribbean 2017. OECD Publishing, Paris.

OECD (2017a). Government at a Glance 2017. OECD Publishing, Paris.

OECD (2017b). Measuring distance to the SDG Targets. An assessment of where OECD countries stand. http://www. oecd.org/sdd/OECD-Measuring-Distance-to-SDG-Targets. pdf, last accessed 13 February 2019.

OECD (2018). 2018 Regulatory Policy Outlook. OECD Publishing, Paris. http://www.oecd.org/gov/oecd-regulatory-policy-outlook-2018-9789264303072-en.htm

OECD (2019a). Better Regulation Practices across the European Union. OECD Publishing, Paris.

OECD (2019b). Civic Engagement. http://www.oecdbetterlifeindex.org/topics/civic-engagement/, last accessed 13 February 2019.

OECD (2019c). Methodology of the iREG composite indicators. http://www.oecd.org/gov/regulatory-policy/Methodology-of-the-iREG-composite-indicators.pdf, last accessed 13 February 2019.
OECD (2019d). Reviewing and supporting Regulatory Impact Assessment in Portugal. Project Inception Report. Final draft. https://www.jurisapp.gov.pt/media/1020/ria-in-pt-finaldraft.pdf, last accessed 13 February 2019.

OECD (forthcoming, a). OECD Best Practice Principles for Regulatory Policy: Regulatory Impact Assessment. OECD Publishing, Paris.

OECD (forthcoming, b). OECD Best Practice Principles for Regulatory Policy: Stakeholder engagement. OECD Publishing, Paris.

OECD (forthcoming, c). OECD Best Practice Principles for Regulatory Policy: Reviewing the Stock of Regulation. OECD Publishing, Paris.

OECD/European Commission/JRC (2008). Handbook on Constructing Composite Indicators: Methodology and User Guide. OECD Publishing, Paris.

Querbach, T. and Arndt, C. (2017). Regulatory policy in Latin America: An analysis of the state of play. OECD Regulatory Policy Working Papers, (7). OECD Publishing, Paris.

Radaelli, C. M. (2018). Regulatory indicators in the European Union and the Organization for Economic Cooperation and Development: Performance assessment, organizational processes, and learning. Public Policy and Administration 0(0), $1-20$.

Regelrådet (2016). Årsrapport 2016. http://regelradet. no/wp-content/uploads/2017/05/arsrapport_Regelraadet_2016-UU-Ferdig-Copy.pdf, last accessed 13 February 2019.

Solomon, S. (2018). Israel could gain from increased competition, public spending, OECD says. Times of Israel, 15 July 2018, in https://www.timesofisrael.com/israel-could-gainfrom-increased-competition-public-spending-oecd-says/, last accessed 13 February 2019.

Trnka, D. and Thuerer, Y. (2019). One-In, X-Out: Regulatory offsetting in selected OECD countries. OECD Regulatory Policy Working Papers, (11). OECD Publishing, Paris.

World Bank Group (2019a). Doing Business. Measuring Business Regulations. http://www.doingbusiness.org/, last accessed 13 February 2019.

World Bank Group (2019b). Worldwide Governance Indicators. http://info.worldbank.org/governance/wgi/, last accessed 13 February 2019.

World Justice Project (n.d.). WJP Rule of Law Index 20172018. https://worldjusticeproject.org/our-work/wjp-rule-lawindex/wjp-rule-law-index-2017\%E2\%80\%932018, last accessed 13 February 2019. 
En el próximo número de

Información Comercial Española. Revista de Economía

\section{España ante el reto demográfico}

Últimos números publicados:

Regulación de mercados y competencia

Demografía y desarrollo económico

Evolución y perspectivas de la población en España

El reto demográfico: la perspectiva de género

El árbol de la población y el mercado de trabajo

La crisis financiera.

Diez años después

Números en preparación:

Multinacionales en un cambiante contexto internacional

Efectos de la inmigración en las pirámides de población

El sistema de pensiones

Natalidad y robotización en un contexto de creciente longevidad

Esperanza de vida y sostenibilidad del sistema sanitario

\section{ICE}

Desigualdad, población y políticas públicas

Un nuevo contrato social

Espania ante el reto demogrtáfico 